Igor PETRUŠKA • Jana CHOVANCOVÁ • Eva LITAVCOVÁ

\title{
DEPENDENCE OF CO2 EMISSIONS ON ENERGY CONSUMPTION AND ECONOMIC GROWTH IN THE EUROPEAN UNION: A PANEL THRESHOLD MODEL
}

Igor Petruška, DSc (ORCID: 0000-0002-2005-3500)

Jana Chovancová, PhD (ORCID: 0000-0002-6699-1244)

Eva Litavcová, Assoc. prof., PhD (ORCID: 0000-0002-5323-4359)

- Faculty of Management, University of Prešov, Prešov, Slovakia

Correspondence address:

Konštantínova 16, 08001 Prešov, Slovakia

e-mail: jana.chovancova@unipo.sk

ABSTRACT: This work aims to analyse the dependence of carbon dioxide $\left(\mathrm{CO}_{2}\right)$ emissions on primary energy consumption at different Gross Domestic Product (GDP) levels in 28 European countries. Data for the years 1995-2019 were used to develop the models. Random Effects, Fixed Effects, a nonlinear panel threshold model and a continuous kink model were used in the panel data analysis. The work shows that the dependence of $\mathrm{CO}_{2}$ emissions on energy consumption varies at different levels of GDP. The model with two threshold values, which determine three modes of behaviour, proves to be the most suitable. As GDP levels increase, the regression coefficient of the dependence of $\mathrm{CO}_{2}$ emissions on energy consumption decreases. Understanding the relationship between these variables is essential for informed and evidence-based decision-making and adopting new or revision of existing energy and climate policies and strategies at the EU and national levels.

KEYWORDS: energy consumption, economic growth, $\mathrm{CO}_{2}$ emissions, panel threshold model, kink model 


\section{Introduction}

Energy plays a crucial role in determining our ability to achieve global sustainability in the short and long run. It is dependent on natural resources and is one of the most important drivers of environmental impacts on the Earth's ecological systems. Easy access to energy was a prerequisite for the rapid improvement of people's living conditions and the rapid growth of the world's population, which began at the beginning of the industrial revolution. Empirical evidence shows that in the mid-1950s, there was a trend called "The Great Acceleration", which is characterised by the exponential use of natural resources and ecosystems and is closely linked to economic growth and growth of global population and energy consumption (Steffen et al., 2007). Negative effects also accompany the increased energy consumption on the environment. Probably the most threatening of these impacts is the significant increase in atmospheric concentrations of greenhouse gases, especially $\mathrm{CO}_{2}$, associated with global climate change (Knutti et al., 2016). Observations of rising global surface temperatures provide evidence that more intense anthropogenic greenhouse gas emissions are causing climate change. The rate of change has been steadily increasing over the last century (IPCC, 2007). Increasing energy consumption per capita and related air pollution, which have historically acted at the local or regional level, now pose a global threat in the form of climate change.

Despite the European Union's growing initiatives to decarbonise the economy and its strong commitment to meet the international goals of the Paris Agreement and the United Nations' Agenda 2030, the energy sector is at the forefront of EU greenhouse gas emissions producers (EEA, 2019).

The aim of the paper is to investigate the linkage among three variables: carbon dioxide $\left(\mathrm{CO}_{2}\right)$ emissions per capita, primary energy consumption (PEC) per capita and gross domestic product (GDP) per capita in 28 EU countries in the period of 1995-2019 using panel threshold models. Panel data offer advantages over cross-sectional data or time series, mainly because they make it possible to compare mutual deviations between individual cross-sectional units and also deviations in time evolution. Panel analysis enables better control of the influence of unclassified variables, easier detection of homogeneity or heterogeneity in the data and easier observation of the dynamics of changes. The obtained threshold values make it possible to assess at what degree of economic growth we can expect mitigation of the negative environmental effects, such as a reduction in $\mathrm{CO}_{2}$ emissions. LSDV regression model allows the comparisons of the development between countries. The analysis' results can be used to help individual stakeholders make 
educated and responsible decisions, as well as to harmonise environmental, energy, and economic policies.

The paper is organised as follows. First, literature and policy background is described, with the focus on previous studies in the field of energy, economy and $\mathrm{CO}_{2}$ emissions nexus and recent policy initiatives of the $\mathrm{EU}$ in the field of climate and energy policy. The research methods and data are described in Section 2. The results are presented in the third section, which is followed by a discussion of the findings in the fourth section. The last section concludes the paper.

\section{Literature and policy review}

The environmental economy is particularly interested in the relationship between economic growth, energy consumption, and the production of anthropogenic greenhouse gas emissions. Many authors investigate and discuss the topic of economy-energy-emissions nexus, both at the country and international level, and they use a diverse methodological apparatus. International studies were carried out by, e.g. (Ozcan \& Ari, 2017) for OECD countries, where they investigated nuclear energy-economic growth nexus using panel data analysis. (Chang, 2015) employed data envelopment analysis to investigate energy intensity, emissions intensity and carbonisation value in G7 and BRICS (Brazil, Russia, India, China, and South Africa) countries and to suggest the possibilities for improvement in both groups. (Kahouli, 2018) scrutinise the causal relationship between electricity consumption, carbon emissions, investments in research and development and economic growth in Mediterranean countries. (Balcilar et al., 2020) took a historical perspective on the $\mathrm{G} 7$ countries and investigated the causality between $\mathrm{CO}_{2}$ emissions, energy consumption and economic growth. Nexus between the three variables in the Next 11 countries was investigated by (Shahbaz et al., 2016). Evidence of cointegration among $\mathrm{CO}_{2}$ emissions, energy consumption and economic growth in Danube region countries was provided by Litavcová \& Chovancová (2021). The relationship between economic growth, $\mathrm{CO}_{2}$ emissions and energy consumption in V4 was scrutinised by Chovancová \& Vavrek (2020), where decoupling analysis was performed, and evidence of mitigation effect of renewable sources was confirmed.

A comparative study of the relationship among economic growth, trade, urbanisation, renewable energy and $\mathrm{CO}_{2}$ emissions for Australia and Canada was performed by (Rahman \& Vu, 2020), which provides evidence of the long-run relationships amongst the variables. 
A worldwide perspective was taken by (Armeanu et al., 2021), who scrutinise a link between economic growth, renewable energy, $\mathrm{CO}_{2}$ emissions, and urbanisation in 106 countries and confirm the long-term relationship among these variables.

Similar studies in the country level were performed by, e.g. (Han et al., 2018; S. Wang et al., 2016; Zhang \& Cheng, 2009) for China, for (Ahmad et al., 2016; Alam et al., 2011) for India, (Gökmenoğlu \& Taspinar, 2016) for Turkey, (Robalino-López et al., 2015) for Venezuela, (Khan et al., 2019) for Pakistan, etc.

Efforts to decarbonise the economy and the associated climate change mitigation are also a central theme in the European Union. Over the last decade, this approach has been embedded in important policy initiatives, such as climate and energy policies for 2030 and 2050, circular and bio-economy packages, as well as research and innovation programs. In addition, the 7th EAP is fully in line with global objectives such as the 2030 Agenda for Sustainable Development and the Paris Agreement on Climate Change.

Proposed long-term strategy European Green Deal, which aims to achieve carbon neutrality by 2050 , emphasises that the options it proposes "radically transform energy systems as well as the agricultural sector and modernise industrial infrastructure along with transport systems and cities and affect all activities of the whole society". This long term strategy also recognises the need for a "transition to a low-carbon, climate-neutral, resource-efficient economy" (EC, 2019), which is fully in line with the United Nations Agenda 2030 and its seventeen sustainable development goals.

In the light of these challenges, there is a need for regular monitoring, analysis and evaluation of the development of key economic, energy and environmental indicators as well as the relationships between them. Due to the complexity of this assessment, statistical tools must be used to collect and evaluate selected characteristics (indicators), which provide a solid knowledge base for making informed and responsible decisions, including those related to energy and climate protection policies.

\section{Research methods}

The paper investigates the relationship between economic growth, primary energy consumption and carbon dioxide emissions in the EU 28 during 1995-2019. Data were drawn from several sources: GDP per capita in purchasing power parity (thousands of current international \$) from The World Bank Database, primary energy consumption per capita (MWh) from BP Sta- 
tistical Review of World Energy and carbon dioxide emissions per capita (tons) from the Global Carbon Project.

The data used in the panel structure consist of: number of countries $N=28$, number of periods (years) $T=25$, number of monitored variables $k=3$. Total 2100 data. The models were developed using Stata 15.1 software.

A panel data regression differs from a regular time-series or cross-section regression - it has double subscript on its variables (Baltagi, 2005):

$$
y_{i t}=\alpha+X_{i t}^{\prime} \beta+\mu_{i}+v_{i t}, \quad t=1, \ldots, T, \quad i=1, \ldots, N,
$$

with $i$ denoting individuals - individuals, firms, countries (cross-section dimension), $t$ denoting time (time-series dimension), $\alpha$ is a scalar, $\beta$ is $K \times 1$ vector and $X_{i t}$ is the $i$-th observation on $K$ explanatory variables. The character $\mu_{i}$ denotes the unobservable time-invariant individual-specific effect, $v_{i t}$ denotes the remainder disturbance, $y_{i t}$ denotes $i t$-th value of a dependent variable. The assumption is the independence of $X_{i t}$ and $v_{i t}$ disturbances are independent of each other. Random errors $v_{i t}$ are independent random variables with constant variance. For a model with fixed effects (FE) the assumption of a correlation between the entity's error term (individual-specific) and the prediction variables is expected to be met (Litavcová et al., 2020). $\mathrm{FE}$ removes the effect of those time-invariant characteristics. For model with random effects (RE): can be assumed random have to be fulfilled the assumptions: $\mu_{i} \sim I I D\left(0, \sigma_{\mu}{ }^{2}\right), v_{i t} \sim I I D\left(0, \sigma_{\mu}{ }^{2}\right)$, they do not depend on each other, nor with prediction variable.

Panel data are measurements of the considered variable for the same set of $\mathrm{N}$ cases (entities, individuals, countries) in several time points $T$, that allow the identification and control of individual effects and dynamics. A limitation of the linear model is the assumption that a monotone change in a predictor variable leads to a monotone change in the dependent variable. If we assume a change in the behaviour of the model after passing a certain threshold value of a variable, then a linear panel regression is not sufficient. A suitable tool then is a panel threshold model with fixed effects. Threshold models are used in the nonlinear modelling of time series.

Hansen (1999) proposed least squares estimation of the threshold and regression slopes using fixed-effects transformations. Wang (2015) introduced a command (xthreg) for implementing this model in Stata.

$$
y_{i t}=X_{i t}^{\prime} \beta_{1} \times I\left(t r v_{i t} \leq r\right)+X_{i t}^{\prime} \beta_{2} \times I\left(t r v_{i t}>r\right)+\mu_{i}+\eta_{t}+\varepsilon_{i t},
$$


where:

$\beta_{1}, \beta_{2}$ - are vectors of coefficients, trv - threshold variable, $r$ - threshold value, $I$ - unit function,

$\mu_{i}-\quad$ unit effect, $\mu_{t}-$ time effect, $\varepsilon_{i t}-$ IID across countries and year, $i-$ country $i=1, \ldots, N, t$ - time (year) $t=1, \ldots T$.

The standard least-squares approach (Hansen, 2000) requires the heterogeneity of all regressors. Caner \& Hansen (2004) relaxed this requirement for endogenous regressors, but the assumption of heterogeneity of the threshold variable remained. Seo et al. (2019) propose a general GMM approach based on first-difference (FD) transformation. They allow both threshold variable and regressors to be hetengenous. Seo et al. (2019) developed Stata command (xthenreg) to implement the first-differenced GMM estimation of the dynamic panel threshold model proposed by Seo \& Shin (2016).

The threshold models we have mentioned so far contain discontinuities, which is why we also call them jump models. If we replace one of the members containing the difference coefficient in relation (2) with the expression we get the kink model (Hansen, 2017):

$$
y_{i t}=\beta \operatorname{trv}_{i t}+k\left(\operatorname{trv}_{i t}-r\right) I\left(\operatorname{trv}_{i t}>r\right)+\mu_{i}+\varepsilon_{i t} .
$$

Seo et al. (2019) derive the asymptotic variance formula for a kink constrained GMM estimator of dynamic threshold model and include an estimation algorithm. It follows from the shape of this model that the threshold variable is the only mode variable of this continuous model.

To test the suitability and validity of the models, these statistical tests $(\alpha=0.05)$ were performed:

- F test of significance of the FE model,

- Wald test of significance of the RE model,

- $\quad \mathrm{F}$ test that all $=0$,

- $t$ test of significance of regression coefficients,

- Hausman FE RE test,

- Breusch and Pagan Lagrangian multiplier test for random effects,

- Pesaran test of cross sectional independence,

- Modified Wald test for groupwise heteroscedasticity in FE model,

- Confidence interval of threshold value test,

- Threshold effect test (bootstrap). 


\section{Results of the research}

Our goal is to find the dependence of $\mathrm{CO}_{2}$ on economic growth (GDP) and primary energy consumption (PEC). Therefore, we will consider $\mathrm{CO}_{2}$ as a dependent variable and GDP and PEC as independent variables. At the beginning of the search for suitable models, a simple descriptive statistic of the analysed data was performed. Descriptive statistics, including the variable's name, units, the number of observations, mean values, standard deviation and minimum and maximum values, are summarised in table 1.

Table 1. Descriptive statistics of analysed variables

\begin{tabular}{llllllll}
\hline Variable & Abb & Unit & Obs & Mean & Std.Dev & Min & Max \\
\hline Carbon dioxide emissions & $\mathrm{CO}_{2}$ & tons per cap & 700 & 8.180 & 3.556 & 2.963 & 26.431 \\
\hline Gross Domestic Product & GDP & th EUR per cap & 700 & 29.815 & 16.438 & 5.415 & 124.590 \\
\hline Primary Energy Consumption & PEC & MWh per cap & 700 & 35.958 & 16.946 & 17.565 & 119.260 \\
\hline
\end{tabular}

Source: own processing - in Stata.

It is also useful to know the scatterplots of the pairs of variables appearing in the model. The relationship between the variables $\mathrm{CO}_{2}$, GDP and PEC is shown in figure 1.

The strongest link appears to be between the PEC and $\mathrm{CO}_{2}$. The values of the correlation coefficients in the correlation matrix also correspond to this (table 2). All correlation coefficients are significant ( $\mathrm{p}$-value $=0.00$ ).

Table 2. Correlation matrix

\begin{tabular}{llll}
\hline & GDP & $\mathrm{CO}_{2}$ & PEC \\
\hline GDP & 1.00 & & \\
\hline $\mathrm{CO}_{2}$ & 0.4323 & 1.00 & \\
\hline $\mathrm{PEC}$ & 0.5857 & 0.8146 & 1.00 \\
\hline
\end{tabular}

Source: own processing - in Stata.

The initial analysis of the data and the results of the descriptive statistics show a strong heterogeneity of the countries studied.

The highest heterogeneity is recorded in the variable PEC, where are significant differences between countries. The countries with the lowest primary energy consumption per capita are Romania, Malta and Croatia, where the PEC in 2019 was 19,209 kWh, 20,129 kWh and 23,474 kWh, respectively. 

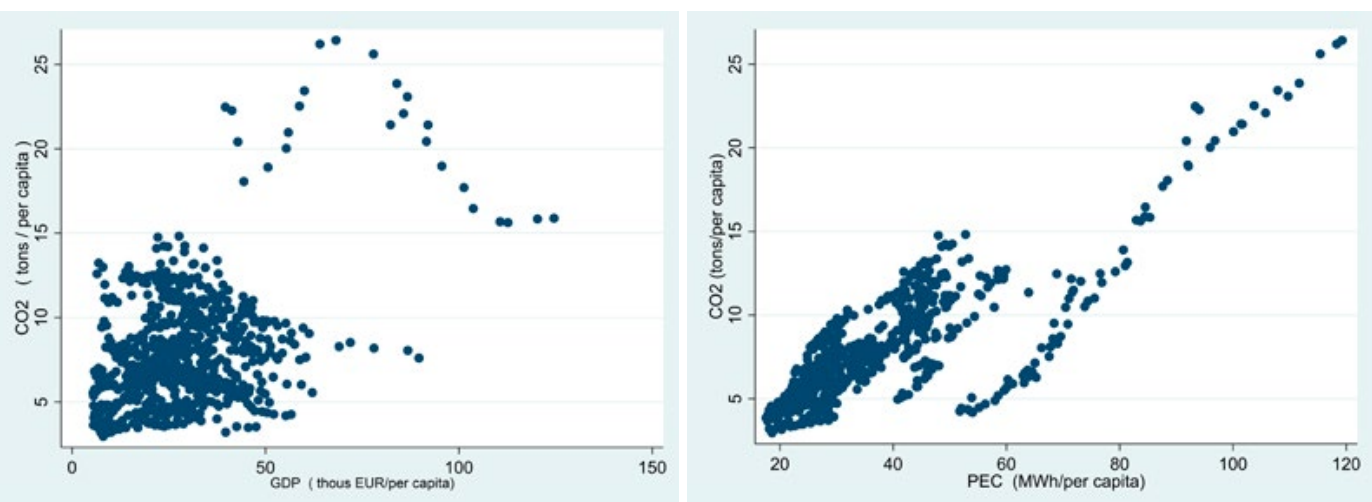

Figure 1. Scatter diagram of pairs of $\mathrm{CO}_{2}, \mathrm{GDP}, \mathrm{PEC}$

Source: own processing - in Stata.

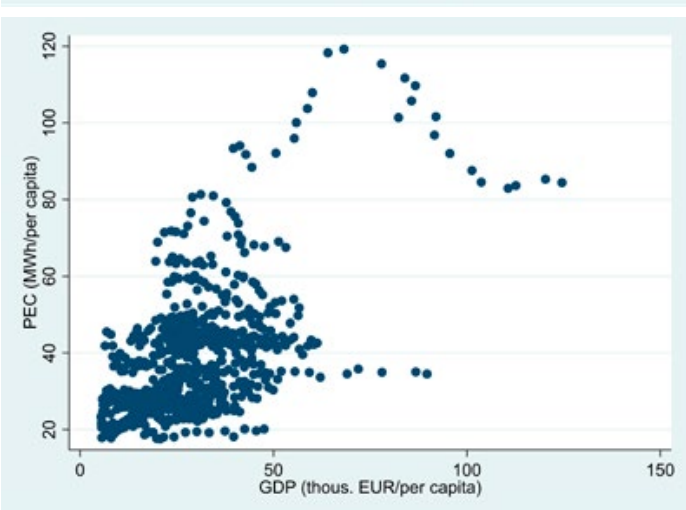

The largest consumers of primary energy in 2019 were Luxembourg, Finland and Sweden, where the PEC reached the level of $84,425 \mathrm{kWh}, 67,543 \mathrm{kWh}$ and $51,765 \mathrm{kWh}$, respectively.

GDP per capita also has a high heterogeneity of data. Luxembourg, Ireland and Denmark were at the top of the GDP in 2019, with per capita GDP of $€ 124,950$, $€ 89,684$ and $€ 62,090$, respectively. On the other side of the spectrum were Bulgaria, Croatia and Greece, with a GDP per capita of $€ 25,312$, $€ 31,311$, € 32,506 recpectively.

Low heterogeneity was recorded in the amount of $\mathrm{CO}_{2}$ emissions produced per capita. For example, Sweden has the lowest $\mathrm{CO}_{2}$ emissions per capita (4.25 t) and Luxembourg the highest (15.88 t).

The Stata-xtreg module was used to calculate the regression coefficients of the panel threshold models (Fixed Effects, Random Effects). Next, the parameters of the Pooled model (OLS) were compared with the panel data analysis models. The results show that all coefficients of the calculated models (except the absolute term in the Random effects model) are significant. Slope coefficients (GDP, PEC) have the same sign. 
Table 3. Panel data models

\begin{tabular}{lllllll}
\hline \multirow{2}{*}{$\mathrm{CO}_{2}$} & \multicolumn{2}{l}{ Pooled model } & \multicolumn{2}{l}{ Fixed Effects } & \multicolumn{2}{l}{ Random Effects } \\
\cline { 2 - 7 } & Coef & $\mathrm{p}$-value & Coef & $\mathrm{p}$-value & Coef & $\mathrm{p}$-value \\
\hline $\mathrm{GDP}$ & -0.0147 & 0,012 & -0.0407 & 0.000 & -0.0412 & 0.000 \\
\hline $\mathrm{PEC}$ & 0.1793 & 0.000 & 0.2544 & 0.000 & 0.2510 & 0.000 \\
\hline Cons & 1.634 & 0.000 & -0.5183 & 0.025 & -0.3693 & 0.397 \\
\hline F test & 696.69 & 0.000 & 1895.11 & 0.000 & & \\
\hline Wald test & & & & & 3780.2 & 0.000 \\
\hline F test that all $=0$ & & & & & \\
\hline
\end{tabular}

Source: own processing - in Stata.

Tests ( $\mathrm{F}$ test, Wald test and $\mathrm{F}$ test that all $=0$ ) showed that all three models are relevant ( $\mathrm{p}$-value is less than 0.05).

We can say that in all three cases, GDP growth causes a decrease in $\mathrm{CO}_{2}$, and an increase in energy consumption (PEC) causes higher $\mathrm{CO}_{2}$ production.

The coefficient of determination (R-squared) in the case of the Pooled model reaches the size of 0.666 and corr $\left(\mu \_\mathrm{i}, \mathrm{Xb}\right)=-0.4668$ (Fixed effects). In the next step, we will choose the most suitable model from these three models. Breusch and Pagan Lagrangian multiplier test for random effects helps us to decide between random effects regression and simple OLS (Pooled model) regression (H0: No panel effects - Var $=0$ ). Since the p-value is less than 0.05 , this means that we reject the Pooled model (OLS) and state that panel effects are applied in the model.

Table 4. Panel data model tests

\begin{tabular}{ll}
\hline Test & p-value \\
\hline Breusch and Pagan Lagrangian multiplier test for random effects & 0.000 \\
\hline Hausman FE RE test & 0.0179 \\
\hline Pesaran test of cross-sectional independence & 0.0141 \\
\hline Modified Wald test for groupwise heteroskedasticity in FE model & 0.000 \\
\hline
\end{tabular}

Source: own processing - in Stata.

To decide between fixed or random effects, we can run Hausman test where the null hypothesis is that the preferred model is random effects vs the alternative fixed effects. The P-value in the case of this test is $0.0179<0.05$, 
which means that we choose a fixed-effects model, which can be expressed by the following relation:

$$
\mathrm{CO}_{2}=-0.5183-0.0407 G D P+0.2544 P E C
$$

According to this model, if energy consumption is increased by $1 \mathrm{MWh}$ per capita, $\mathrm{CO}_{2}$ emissions per capita will increase by 0.25 tons per capita, and an increase in GDP per capita (thousand $€$ ) represents a decrease in $\mathrm{CO}_{2}$ emissions by 0.0407 tons per capita.

We can also differentiate individual countries using the specific constant $\mu_{i}$. Specific constants obtained by the Least Squares Dummy Variable Model (LSDV) are given in table 5.

Table 5. Least Squares Dummy Variable Model

\begin{tabular}{llllll}
\hline Country & Coef & p-value & Country & Coef & p-value \\
\hline AUT (cons) & -0.910 & 0.001 & ITA & 1.468 & 0.000 \\
\hline BEL & -0.711 & 0.000 & LTA & -0.799 & 0.000 \\
\hline BGR & 0.699 & 0.000 & LT & -0.634 & 0.000 \\
\hline HRV & 0.540 & 0.003 & LUX & -0.195 & 0.577 \\
\hline CYP & 2.266 & 0.000 & MLT & 1.750 & 0.000 \\
\hline CZE & 1.724 & 0.000 & NLD & 0.878 & 0.000 \\
\hline DNK & 1.371 & 0.000 & POL & 3.118 & 0.000 \\
\hline EST & 2.900 & 0.000 & SVN & -0.067 & 0.627 \\
\hline FIN & -5.270 & 0.000 & SVK & 0.120 & 0.413 \\
\hline FRA & -2.819 & 0.000 & ESP & 0.812 & 0.000 \\
\hline DEU & 1.628 & 0.000 & ROU & 0.999 & 0.000 \\
\hline GRC & 3.376 & 0.000 & PRT & 1.102 & 0.000 \\
\hline HUN & 0.020 & 0.899 & SWE & -7.067 & 0.000 \\
\hline IRL & 3.020 & 0.000 & GBR & 0.756 & 0.000 \\
\hline
\end{tabular}

Source: own processing - in Stata.

As a reference country, we chose AUT, which corresponds to the absolute term - 0.910. Regression coefficients for the variables GDP and PEC are given in Table 3 for Fixed effects. Country-specific constants are obtained by adding the number given in the table (Coef) to the number -0.910. Again, we can say that these are very heterogeneous data because the differences are signif- 
icant with up to 4 exceptions: Hungary, Luxembourg, Slovenia, and Slovakia. The largest positive differences with the reference country (AUT) were recorded in Cyprus, Estonia, Greece, Ireland and Poland. These countries have a high share of $\mathrm{CO}_{2}$ emissions per capita. These are countries whose economies are carbon-intensive, and low-carbon energy sources are under-represented in their energy mix. For example, in Poland, despite the declining trend of the main air pollutants (Pakulska, 2021) and stringent environmental policy (Godawska, 2021); in terms of the amount of $\mathrm{CO}_{2}$ emissions produced per capita, this country is one of the most polluted among the EU countries, mainly due to extensive use of coal as an energy source.

On the other hand, the largest negative differences are in Finland, France and Sweden, i.e. they are the countries with the lowest share of $\mathrm{CO}_{2}$ emissions per capita. Sweden and Finland are at the forefront of renewable energy; in the case of Sweden, renewable energy sources have a $56.4 \%$ share in the energy mix and in the case of Finland, it is $43.1 \%$ in 2019. In France, the dominant source is nuclear energy, which is $71.6 \%$ of the country's energy mix. As it is also low-carbon energy in a way, it has secured France's prominent position in terms of per capita $\mathrm{CO}_{2}$ emissions.

In the next part, we will deal with the analysis of residues obtained using fixed effects. The Pesaran CD (cross-sectional dependence) test is used to test whether the residuals are correlated across entities (countries). Cross-sectional dependence can lead to bias in test results (also called contemporaneous correlation). The null hypothesis is that residuals are not correlated. According to the p-value in table 4, we reject the null hypothesis. Modified Wald test for groupwise heteroscedasticity in FE model has null hypothesis - homoscedasticity (or constance variance). Above we reject the null and conclude heteroscedasticity.

We will use the threshold model in the following analysis since the Fixed effects model shows signs of cross-correlation and heteroscedasticity. As it describes the jump character or structural breaks in the relationship between variables, we also call them jump models. For simplicity, we will only present a panel threshold model with one threshold value.

$$
\begin{aligned}
& C O_{2 i t}=\beta_{0}+\beta_{1} P E C_{i t} I\left(G D P_{i t} \leq r\right) \\
& +\beta_{2} P E C_{i t} I\left(G D P_{i t}>r\right)+\mu_{i}+\varepsilon_{i t}
\end{aligned}
$$

where :

$\beta_{1}, \beta_{2}$ coefficients, $r$ - threshold value,

$I$ - unit function, $\mu_{i}$ - country effect,

$\varepsilon_{i t}-$ IID across countries and year. 
This means that the threshold model in our case has one regional (regime) variable - PEC and one threshold variable - GDP. Assume that this model can have up to three thresholds. An estimate of these thresholds with confidence intervals is given in table 6 .

Table 6. Threshold estimator

\begin{tabular}{llll}
\hline Model & Threshold & Lower & Upper \\
\hline Th - 1 & 30.788 & 30.588 & 30.818 \\
\hline Th- 21 & 41.493 & 41.297 & 41.643 \\
\hline Th-22 & 22.641 & 22.480 & 22.688 \\
\hline Th-3 & 30.952 & 30.582 & 30.926 \\
\hline
\end{tabular}

Source: own processing - in Stata.

The bootstrap test for the threshold effect is shown in table 7 . Since the Single and Double options have a p-value less than 0.05 and the Triple option greater than 0.05 , then we will select a model with two threshold values $(22,641 €$ and $41,493 €$ respectively) for the model we are looking for. The model will therefore have three modes (table 7).

Table 7. Threshold effect test (bootstrap $=300300300$ )

\begin{tabular}{lll}
\hline Threshold & F-stat & p-value \\
\hline Single & 223,19 & 0,0067 \\
\hline Double & 118.60 & 0.0267 \\
\hline Triple & 67.27 & 0.733 \\
\hline
\end{tabular}

Source: own processing - in Stata.

The Stata-xthreg module was used to calculate the regression coefficients of the panel threshold model. The regression coefficients for individual modes are given in table 8.

Table 8. Panel threshold model

\begin{tabular}{llllll}
\hline $\mathrm{CO}_{2}$ & Region & GDP & Coef & $\mathrm{t}$ & $\mathrm{p}$ - value \\
\hline \multirow{3}{*}{$\mathrm{PEC}$} & Region1 & GDPit $\leq 22.641$ & 0.298 & 51.17 & 0.000 \\
\cline { 2 - 6 } & Region2 & $22.641<$ GDPit $\leq 41.493$ & 0.277 & 50.22 & 0.000 \\
\cline { 2 - 6 } & Region3 & $41.493<$ GDPit & 0.260 & 43.35 & 0.000 \\
\hline \multirow{2}{*}{ cons } & & & -2.681 & -12.11 & 0.000 \\
\hline
\end{tabular}

Source: own processing - in Stata. 
If GDP per capita is less than or equal to $€ 22,642$, then an increase in energy consumption by $1 \mathrm{MWh}$ per capita will cause an increase in $\mathrm{CO}_{2}$ emissions by 0.298 tons per capita. If GDP is in the range of $€ 22,641$ to $€ 41,493$, an increase in energy consumption of $1 \mathrm{MWh}$ means an increase in $\mathrm{CO}_{2}$ emissions of 0.277 tons per capita. In the third case, if GDP exceeds the level of $€ 41,493$, an increase in energy consumption by $1 \mathrm{MWh}$ pc will cause an increase in emissions by 0.26 tons per capita. According to this model, countries with higher GDP are less sensitive to an increase in $\mathrm{CO}_{2}$ emissions in case of an increase in energy consumption.

The panel threshold model shows that we can consider the regression coefficients as significant in all three modes. Another interesting fact is that as the value of the threshold variable (GDP) increases, the regression coefficient for PEC decreases. Thus, with the increase in GDP, the impact of the growth of energy consumption (PEC) on the growth of $\mathrm{CO}_{2}$ emissions decreases.

The previous model is a discontinuous threshold model (Jump model). Next, we will use a continuous panel threshold model (Kink model).

$$
C O_{2 i t}=\beta^{*} G D P_{i t}+k\left(G D P_{i t}-r\right) I\left(G D P_{i t}>r\right)+\mu_{i}+\varepsilon_{i t}
$$

Again we will use the module Stata - xthreg. The model parameters are listed in table 9.

Table 9. Kink model

\begin{tabular}{llll}
\hline $\mathrm{CO}_{2}$ & Coef & $z$ & $p$-value \\
\hline GDP_b & 0.066 & 10.08 & 0.000 \\
\hline Kink slope & -0.2613 & -22.12 & 0.000 \\
\hline$r$ & 40.226 & 79.44 & 0.000 \\
\hline
\end{tabular}

Source: own processing - in Stata.

$$
C O_{2 i t}=0.066 G D P_{i t}-0.2613\left(G D P_{i t}-40.226\right) I\left(G D P_{i t}>40.226\right)
$$

All parameters of the kink model are significant. The threshold value of the 40.226 kink model is close to the second limit value of the jump model (41.93). The model has an inverted $V$ shape with a vertex at point 40. 226. As GDP grows, so does $\mathrm{CO}_{2}$ emissions (coefficient 0.66), but after exceeding the threshold value of $40.226, \mathrm{CO}_{2}$ emissions begin to decline. This supports the EKC's hypothesis that economic growth is not necessarily linked to 
increasing environmental pollution and after reaching a certain level of economic development, the rate of environmental pollution, e.g. in the form of $\mathrm{CO}_{2}$ emissions, is mitigating. This could be due to the transformation of the economy from a production-oriented to a service economy and greater opportunities for investment in innovation, efficiency, and decarbonisation measures.

\section{Conclusions}

Climate change is increasingly affecting the life and functioning of society as a whole. Current initiatives to adopt and implement policies to mitigate and adapt to climate change, whether at a global or regional level, also respond to this challenge. The European Union, which is considered a leader in the fight against climate change, is adopting ambitious climate and energy policies and strategies that should make Europe the first carbon-neutral continent. In the light of these initiatives, the question of the interconnection and relationship between economic growth, energy consumption and greenhouse gas emissions is raised.

Based on the analysis of panel data, we created a model of the dependence of these three variables for the 27 EU Member States in the period 19952019.

In the first stage, we used a linear approach - panel data analysis - Fixed effects model. All coefficients in this model are significant. The model shows that with the growth of primary energy consumption, $\mathrm{CO}_{2}$ emissions increase, but with GDP growth, $\mathrm{CO}_{2}$ emissions decrease. Since the Fixed effects model shows signs of heteroscedasticity and cross-correlation, we used a nonlinear approach in another - the panel threshold model. We chose the GDP variable as a threshold variable. A model with two threshold values proves to be optimal. It can be seen from the calculated parameters of the model that the regression coefficient at PEC decreases with the increasing value of the threshold variable (GDP). Thus, as GDP increases, the impact of energy consumption (PEC) on $\mathrm{CO}_{2}$ emissions decreases.

Finally, a continuous Kink model was used, where the threshold variable is at the same time an independent variable. GDP was chosen as the threshold variable. The threshold value of the Kink model is close to the second threshold value of the Jump model. The kink model (function) has the shape of an inverted V, i.e. the function increases up to the threshold value (the effect of GDP on $\mathrm{CO}_{2}$ is positive) and from the threshold value, the function decreases (the effect of GDP on $\mathrm{CO}_{2}$ is negative). 
Economic growth is linked to energy consumption, which often causes greenhouse gas emissions. However, the results of our analysis provide evidence that after reaching a certain level of economic growth, the production of $\mathrm{CO}_{2}$ emissions is reduced.

Based on the literature and policy review and the findings of the analysis, the following practical implications emerge:

- The results suggest that there is a high heterogeneity between the countries and that there is a gap, especially in terms of the share of $\mathrm{CO}_{2}$ emissions per capita. More activities should be implemented to increase cohesion and cooperation between countries and better transfer of know-how and BAT (Best Available Techniques).

- Decision-makers should review existing or adopt new policies to optimise the energy mix, with a greater emphasis on low-carbon and renewable energy sources.

- Governments (whether at the EU or national level) should support research and development of technologies to use new, renewable and low-carbon energy sources and support their practical application.

- Businesses should be motivated to invest in increasing energy efficiency and developing and implementing new low-carbon technologies.

The analysis results can serve as a springboard for further research on the relationship between the economy and the environment, e.g., the extension of the spectrum of variables such as renewable sources, research and development, and economic openness.

\section{Acknowledgements}

This research has been supported by Scientific Grant Agency of the Ministry of Education, Science, Research and Sport of the Slovak Republic and the Slovak Academy of Sciences within the project 1/0508/21 and Grant Agency for PhD Students and Young Scientific and Pedagogical Staff of the University of Prešov in Prešov GAMA 20/8.

\section{The contribution of the authors}

Each author participated equally in conception, development, literature review, data acquisition, analysis and interpretation of data.

\section{References}

Ahmad, A., Zhao, Y., Shahbaz, M., Bano, S., Zhang, Z., Wang, S., Liu, Y., 2016. Carbon emissions, energy consumption and economic growth: An aggregate and disaggregate analysis of the Indian economy, Energy Policy, 96, 131-143, https://doi. org/10.1016/j.enpol.2016.05.032. 
Alam, M. J., Begum, I. A., Buysse, J., Rahman, S., Van Huylenbroeck, G., 2011. Dynamic modeling of causal relationship between energy consumption, $\mathrm{CO}_{2}$ emissions and economic growth in India. Renewable and Sustainable Energy Reviews, 15(6), 3243-3251.

Armeanu, D. S., Joldes, C. C., Gherghina, S. C., Andrei, J. V., 2021. Understanding the multidimensional linkages among renewable energy, pollution, economic growth and urbanisation in contemporary economies: Quantitative assessments across different income countries' groups. Renewable and Sustainable Energy Reviews, 142(February), https://doi.org/10.1016/j.rser.2021.110818.

Balcilar, M., Ozdemir, Z. A., Tunçsiper, B., Ozdemir, H., Shahbaz, M., 2020. On the nexus among carbon dioxide emissions, energy consumption and economic growth in G-7 countries: new insights from the historical decomposition approach. Environment, Development and Sustainability, 22, 8097-8134, https://doi.org/10. 1007/s10668-019-00563-6.

Baltagi, B. H., 2005. Econometric Analysis of Panel data. John Wiley \& Sons.

Caner, M., Hansen, B. E., 2004. Instrumental variable estimation of a threshold model. Econom Theory, 20, 813-843, https://doi.org/10.1017/S026646660420501 1.

Chang, M. C., 2015. Room for improvement in low carbon economies of G7 and BRICS countries based on the analysis of energy efficiency and environmental Kuznets curves. Journal of Cleaner Production, 99, 140-151, https://doi.org/10.1016/j. jclepro.2015.03.002.

Chovancová, J., Vavrek, R., 2020. (De)coupling Analysis with Focus on Energy Consumption in EU Countries and Its Spatial Evaluation. Polish Journal of Environmental Studies, 29(3), 2091-2100, https://doi.org/10.15244/pjoes/110613.

EC, 2019. Towards a sustainable Europe by 2030, Reflection paper, European Commission.

EEA, 2019. Trends and projections in Europe 2020, https://www.eea.europa.eu/ publications/trends-and-projections-in-europe-1.

Godawska, J., 2021. Environmental policy stringency and its impact on air pollution in Poland. Ekonomia i Środowisko-Economics and Environment, 76(1), 52-67, https://ekonomiaisrodowisko.pl/journal/article/view/359.

Gökmenoğlu, K., Taspinar, N., 2016. The relationship between $\mathrm{CO}_{2}$ emissions, energy consumption, economic growth and FDI: the case of Turkey. The Journal of International Trade \& Economic Development, 25(5), 706-723, https://doi.org/10.10 80/09638199.2015.1119876.

Han, J., Du, T., Zhang, C., Qian, X., 2018. Correlation analysis of $\mathrm{CO}_{2}$ emissions, material stocks and economic growth nexus: Evidence from Chinese provinces. Journal of Cleaner Production, 180, 395-406, https://doi.org/10.1016/j.jclepro.2018.01.168.

Hansen, B. E., 1999. Threshold effects in non-dynamic panels: estimation, testing, and inference. Econom, 93, 345-368, https://doi.org/10.1016/S0304-4076(99) 00025-1.

Hansen, B. E., 2017. Regression Kink with an unknown threshold. Journal of Business \& Economic Statistics, 35(2), 228-240, https://doi.org/10.1080/07350015.201 5.1073595.

IPCC, 2007. Climate Change 2007 Synthesis Report. In Intergovernmental Panel on Climate Change [Core Writing Team IPCC, https://doi.org/10.1256/004316502 320517344.

Kahouli, B., 2018. The causality link between energy electricity consumption, $\mathrm{CO}_{2}$ emissions, R\&D stocks and economic growth in Mediterranean countries (MCs). Energy, 145, 388-399. https://doi.org/10.1016/j.energy.2017.12.136. 
Khan, M. K., Teng, J. Z., Khan, M. I., Khan, M. O., 2019. Impact of globalisation, economic factors and energy consumption on $\mathrm{CO}_{2}$ emissions in Pakistan. Science of the Total Environment., 688, 424-436, https://doi.org/10.1016/j.scitotenv.2019.06. 065.

Knutti, R., Rogelj, J., Sedláček, J., Fischer, E. M., 2016. A scientific critique of the twodegree climate change target. Nature Geoscience, 9(1), 13-18, https://doi.org/ https://doi.org/10.1038/ngeo2595.

Litavcová, E., Popovičová, M., etruška, I., 2020. Threshold analysis of tourism indicators of selected countries of EU. 38th International Conference on Mathematical Methods in Economics. Electronic Conference Proceedings (Eds. Svatopluk Kapounek, Hana Vránová). Mendelova Univerzita v Brně., 350-356.

Litavcová, Eva, Chovancová, J., 2021. Economic development, $\mathrm{CO}_{2}$ emissions and energy use nexus-evidence from the danube region countries. Energies, 14(11), https://doi.org/10.3390/en14113165.

Ozcan, B., Ari, A., 2017. Nuclear energy-economic growth nexus in OECD countries: a panel data analysis. Journal of Economic \& Management Perspectives, 11(1), 138-154.

Pakulska, J., 2021. Emissions of major air pollutants as an indicator of quality of life in Poland in 1990-2017. Ekonomia i Środowisko-Economics and Environment, 76(1), 106-119, https://doi.org/10.34659/2021/1/6.

Rahman, M. M., Vu, X. B., 2020. The nexus between renewable energy, economic growth, trade, urbanisation and environmental quality: a comparative study for Australia and Canada. Renewable Energy, 155, 617-627, https://doi.org/10.1016 /j.renene.2020.03.135.

Robalino-López, A., Mena-Nieto, Á., García-Ramos, J. E., Golpe, A. A., 2015. Studying the relationship between economic growth, $\mathrm{CO}_{2}$ emissions, and the environmental Kuznets curve in Venezuela (1980-2025). Renewable and Sustainable Energy Reviews, 41, 602-614, https://doi.org/10.1016/j.rser.2014.08.081.

Seo, M., Kim, S., Kim, Y. J., 2019. Estimation of Dynamic Panel Treshold Model using Stata.StataJournal,19(3),685-697,https://doi.org/10.1177/1536867X19874243.

Seo, M., Shin, Y., 2016. Dynamic panels with treshold effect and endogeneity. Journal of Econometrics, 195, 169-186, https://doi.org/10.1016/j.jeconom.2016.03.005.

Shahbaz, M., Mahalik, M. K., Shah, S. H., Sato, J. R., 2016. Time-varying analysis of $\mathrm{CO}_{2}$ emissions, energy consumption, and economic growth nexus: Statistical experience in next 11 countries. Energy Policy, https://doi.org/10.1016/j.enpol.2016. 08.011 .

Steffen, W., Crutzen, J., McNeill, J. R., 2007. The Anthropocene: Are humans now overwhelming the great forces of Nature? Ambio, 36(8), 614-621, https://doi. org/10.1579/0044-7447.

Wang, Q., 2015. Fixed-effect panel threshold model using Stata. The Stata Journal, 15(1), 121-134, https://www.stata-journal.com/article.html?article=st0373.

Wang, S., Li, Q., Fang, C., Zhou, C., 2016. The relationship between economic growth, energy consumption, and $\mathrm{CO}_{2}$ emissions: Empirical evidence from China. Science of the Total Environment, https://doi.org/10.1016/j.scitotenv.2015.10.027.

Zhang, X. P., Cheng, X. M., 2009. Energy consumption, carbon emissions, and economic growth in China. Ecological Economics, 68, 10, 2706-2712, https://doi. org/10.1016/j.ecolecon.2009.05.011. 